\title{
UNA PINTURA DESCONOCIDA DE MANUEL DE EGHAVE
}

Nelly Sigaut

\begin{abstract}
En la actualidad surge el problema, reservado a futuros investigadores de cuáles de estos cuadros [de Echeve Ibia] deben catalogarse como de Manuel de Echave Ibía, que viene a resultar ahora más misterioso que su propio hermano, *
\end{abstract}

La pintura mexicana del periodo colonial ofrece al investigador un campo de trabajo poblado de interrogantes. Un desafío compuesto por numerosisimas obras, que desde los muros de iglesias y museos, nos reclaman atención; por artistas que, venidos de otras tierras o nacidos y formados en la Nueva España, permanecen hasta hoy casi desconocidos; por una estructura política-económica - la de la Colonia- que determinaba al productor de imágenes y a la organización que reglamentaba su trabajo: el gremio; y al fin, por una sociedad cuyos valores, básicamente religiosos, determinaban el gusto y por lo tanto incidian notablemente en la producción y consumo de la obra de arte. Dentro de este complejo panorama histórico-artístico, se inscribe una dinastía de attistas, los Echave, que ocuparon cerca de un siglo con sus distintas generaciones.

Ahora bien, la primera cuestión a plantear es: ¿cuántos artistas formaron esta dinastía? La historiografía del tema tiene tres momentos. En el primero claramente se señala la presencia de tres artistas del mismo nombre. En efecto, en el siglo xvir, Carlos de Sigüenza y Góngora en su Triunpho Parténico, se refiere a “...la viveza diestra en pintar las humanas carnes, añadir belleza a la hermosura en la distribución de los colores y hacer verdad la ficción a esfuerzos de dibujo, en las tres líneas o caracteres con que mutuamente diversos, aún más que por el tiempo se dieron a conocer los tres Echaves". " ${ }^{1}$ La obra se publicó en 1683, a un año de la muerte del último pintor de esta familia (Echave Rioja en 1682). Es evidente que la cercanía temporal podría haber hecho conocer a Sigüenza el problema, pero no aclara quiénes son estos tres

* Manuel Toussaint, Arte Colonial en México, México, Imprenta Universitaria, 1974, p. 74 .

1 Carlos de Sigüenza, Triunpho Parténico que en glorias de Maria... celebró la Pontificia, Imperial y Regia Academia Mexicana, Juan de Ribera, 1683, p. 16. 
Echave a los que nombra. Sin embargo, en otras de sus obras, arroja un poco más de claridad sobre este asunto. En las Glorias de Querétaro, dice que "en el altar mayor del templo de Guadalupe, dedicado en 1680, estaba en el segundo cuerpo colocada entre cortinas la imagen de Maria Santísima de Guadalupe, pintada en lienzo por el maestro Baltasar de Echave, tercero de este nombre y no inferior en aquel tiempo en la valentía del dibujo a su abuelo y a su padre". ${ }^{2}$

Sin entrar en otras consideraciones sobre la identidad de estos ratistas. sí es interesante señalar que el dato es claro y no admite confusiones; en el siglo xvir, los Echave conocidos y -evidentemente- admirados, son sólo tres.

Existe casi un siglo entre la última obra mencionada y la Compendiosa Narración de la Ciudad de México, de Juan de Viera, escrita en el siglo xvirt, aunque permaneció inédita hasta 1952. La crónica reproduce la relación de obras que el autor conoció. El testimonio también es claro: en la "Razón de los pintores célebres de la América", bajo el número 7 aparecen registrados Los tres Chávez. ${ }^{3}$ La característica más interesante de esta primera etapa es que se plantea la existencia de tres artistas del mismo nombre, referencia a tener en cuenta en la evolución del problema, pues dará posibilidad a hipótesis posteriores.

Durante el siglo xIx los esfuerzos hechos por varios estudiosos del arte mexicano, abren una segunda etapa historiográfica, que reconoce dos variantes; en una se ubican los autores que señalan la existencia de tres Echave, ya identificados como el viejo, el mozo y un tercero de nombre Manuel. Este es el caso de Lucio, quien en su Reseña Histórica, publicada en 1863, aseguraba que "ha habido otros dos pintores del mismo apellido, hijos de éste [Echave el viejo] Baltazar a quien llamaban el mozo y Manuel". ${ }^{4}$ Misma afirmación que realizó José Bernardo Couto en 1872 "otro tercer Echave [Manuel] hubo hacia el mismo tiempo". 5 La otra variante es presentar solamente a dos Echave, el viejo y el mozo,

2 Carlos de Sigüenza, Glorias de Querétaro, citado en $\mathbf{R}$ " Ruiz Gomar, "Un panorama y dos ejemplos...", tesis para optar por el grado de Licenciado en Historia, UNAM, 1976, p 288,

3 Juan de Viera, Compendiosa Narración de la ciudad de México, México-Buenos Aires, Ed. Guaranía, p. 105.

4 Rafael Lucio, Reseña Histórica de la pintura mexicana en los siglos XVII Y XVIII México, 1864, p. 6

5 José Bernardo Couto, Diálogo sobre la historia de la pintura en México, México, F. C. E., 1947, p. 71. 
tal como lo hizo Manuel Revilla. ${ }^{6}$ Esta era la versión más difundida $\mathrm{y}$ así quedó planteado el problema hasta principios del siglo xx.

El importante aporte de Manuel Toussaint abre la tercera etapa historiográfica del tema: su hipótesis se plantea por primera vez en el Catálogo de Pinturas del Museo Nacional de Artes Plásticas y es notablemente ampliada en la primera edición del Arte Colonial en México, de 1948. En La Pintura Colonial en México, obra terminada en los años treinta, pero que fue publicada de manera póstuma con edición, prólogo y notas de Xavier Moyssén, se encuentra la exposición más completa de esta hipótesis. Esta primera edición es de 1965.

Con respecto a los Echave, el maestro Toussaint propuso la exis. tencia de otro artista del mismo nombre. Baltasar de Echave hijo del primer Echave, quien es conocido desde entonces por su segundo apellido, Ibía, padre de Echave el mozo, Rioja Asi, los que eran conocidos como padre e hijo, pasaron a ser abuelo y nieto Manuel sería - para Toussaint- hermano del recién descubierto Echave Ibía y por lo tanto, también hijo de Echave Orio. ${ }^{7} \mathrm{El}$ aporte de Toussaint culminó en un cuerpo teórico que, moviéndose en el campo de la hipótesis, fue aprobado en la práctica como tesis. El planteo de este autor comienza por el jefe de la familia, a quien Toussaint, como ya se ha dicho, identifica como Baltasar de Echave Orio, natural de Zumaya, de la provincia de Guipúzcoa, en las vascongadas. Según el libro del conde de Urquijo, publiacdo en 1928, Casas y Linajes de Echave y Laurcaiin este artista era "hijo segundo de Juan Martínez de Echave Laurcáin y de su legítima mujer, doña María Juanes de Orio y hermano por tanto del V Señor de la Casa de Echave, Juan Martínez de Echave Orio". ${ }^{8}$

A partir de la fecha de nacimiento del hermano mayor - 1546 - y del testamento que Echave hizo el 23 de septiembre de 1573 ante el escribano Francisco de la Torre -trámite para el cual, según Toussaint, se requería ser mayor de edad-, supone este autor que Echave Orio debió nacer entre 1547/48. Pero, si bien en esta época se consideraba que un indi. viduo era mayor de edad a los veinticinco años, criterio que no varió hasta el siglo xIx (cuando comenzó a considerarse la edad límite de veintiún años) existía otra categoría jurídica denominada mayor infan-

- Manuel Revilla, El arte en México, México, Librería Universal de Porrúa Hnos", 1923 , p. 115.

7 Manuel Toussaint, La pintura colonial en México, México, México, IIE-UNAM, 1965, pp. 86-9.

8 Ibidem. 
cia o menores de veinticinco años, que comprendía las edades de catorce a veinticinco, que permitía a un individuo actuar legalmente, bajo la revisión de un curador.

Por otra parte, existe un documento refexido a un proceso inquisitorial, por el cual se sabe que Echave contaba con treinta y ocho años en 1596 y que era vecino de la ciudad de México, con residencia en la calle de San Francisco. ${ }^{9}$ Por lo tanto, Echave no nació en 1548, sino diez años después, o sea en 1558 y aunque haya algún error en la declaración de la edad, como era común en la época, no sería seguramente de más de dos o tres años. Pero, tomando como cierto el dato documental, se tendría que efectuar la corrección a la primera fecha con la que trabajó Toussaint.

Otra interrogante que queda sin resolver es dónde hizo su testamento Echave Orio. Según Toussaint, lo suscribe "con motivo de haber decidido trasladarse a Sevilla no sabiendo lo que pudiera suceder". ${ }^{10}$ Sin embargo, Carrillo y Gariel indicó que "de Aizarnazábal se trasladó a Sevilla donde hizo testamento ante el escribano Francisco de la Torre, del número de Zumaya”. 11

La argumentación de Toussaint continúa con el problema del paso de Echave Orio a la Nueva España, que este autor ubica inmediata. mente después de 1573 (y que justifica el testamento) fecha desde la cual hasta 1582, se carece de datos del artista. El 9 de diciembre de este último año contrae matrimonio con Isabel de Zumaya Ibía, hija de Francisco de Zumaya, pintor y segundón de la noble Casa Torre de Zumaya y "sólo después de casado empieza su educación artística, puesto que en 1585, en la reparación de la catedral vieja, en que figuran los más famosos artistas que a la sazón estaban en México, incluso su suegro, él no aparece ejecutando el menor trabajo". ${ }^{12}$ Si Echave Orio pasó inmediatamente después de 1573 a la Nueva España, ¿por qué afirmó Toussaint que la formación comenzó después de su boda en 1582? Es evidente que sí tuvo relación con Zumaya, como lo prueba la boda con su hija, es probable que haya sido porque vino confiado a él desde España y que con él estudió desde esas fechas. Es posible también que hubiera participado como aprendiz (tendría, cuando llegó a la Nueva España, quince o dieciséis años) en los talleres de Pereyns o de Concha,

9 Guillermo Tovar, Pintura y Escultura del Renacimiento en México, México, INAH, 1979, p. 181.

10 Manuel Toussaint, ap. cit., p. 87.

11 Colección A. Carrillo y Gariel, exp CACG/250, f. 2700, IIE

12 Manuel Toussaint, op. cit, p. 87. 
sobre todo de este último, con quien guarda grandes relaciones estilísti. cas. Esto explicaría también por qué no aparece en las obras de la catedral de 1585, en las cuales vemos figurar a los más famosos artistas de la época, pero no a los oficiales o aprendices de sus talleres.

Toda esta argumentación conduce directamente al problema de la formación de Echave Orio, cuya conclusión implica una completa visión del desarrollo que había alcanzado la pintura novohispana es el siglo xvi. Durante mucho tiempo no se dudó de la educación artística europea de Echave, no solamente española, sino también italiana. "Era cos. tumbre de nuestros críticos, cuando encontraban un artista de gran fuste, afirmar sin vacilaciones que había llegado formado de la península, por. que no era posible que en México hubiera maestros capaces de producir discípulos tan grandes." 13 Para citar sólo un ejemplo de esta actitud, se reproduce la opinión de Diez Barroso en El Arte en Nueva España: "cualquiera que haya sido el taller en que Echave se formara es incuestionable, como ya se indicó, que llegó a Nueva España en plena posesión de su arte, produciendo desde luego obras de mérito que revelan al artista enteramente formado". ${ }^{14}$

De acuerdo con Toussaint entonces, en que la formación de Echave Orio fue novohispana. La discrepancia estriba en que haya comenzado en la fecha -tardía - de 1582 y que su maestro haya sido Francisco de Zumaya, de quien no se conserva obra conocida y con quien por lo tanto, resulta muy difícil hacer comparaciones estilísticas.

Pero continuando con la argumentaciór del maestro Toussaint se llega a uno de los puntos más cuestionables - a pesar de la aparente lógica- de su hipótesis. Se relaciona con la fecha clave del 17 de diciembre de 1623, en la cual un Baltasar de Echave contrae matrimonio con Ana de Rioja según se asienta en el Libro 4 de matrimonios de espa. noles del Sagrario Metropolitano. Supone el mencionado autor que quien contrae matrimonio no es Echave Orio, sino un hijo suyo del mismo nombre, a quien se conoce desde entonces como Baltasar de Echave Ibía. Si Echave Orio no concurre a la boda de su hijo, dice Toussaint, es porque para esas fechas ya ha muerto: si aún viviera, tendría setenta y cinco años, edad que le parece muy avanzada para emptender la aventura de un nuevo matrimonio. ${ }^{15}$ Pero si se tiene en cuenta

13 Manuel Ioussaint, op cit, p. 56

14 Diez Barroso, El arte en Nueva España, México, 1921, p. 249."

$15 \mathrm{El}$ interés de esta crítica no es demostrar que fue Echave Orio el que se casó en 1623, pues aunque no sabemos si había mucrto para esas fechas, consideramos que sus últimas obras son el San Juan Evangelista, la Inmaculada Concepción de 1620 
la corrección efectuada a partir de la referencia documental ya citada, este artista contaría con sesenta y cinco años, edad que no parece tan descabellada para un segundo compromiso matrimonial. En una época en que las enfermedades y sobre todo los partos, diezmaban con tanta facilidad la población femenina, no eran tan extrañas las dobles - $-y$ hasta triples- nupcias. 16

Que dicho sacramento haya sido administrado por el bachiller Francisco de Echave, de ninguna manera prueba que éste sea hijo de Orio, como creyó Toussaint, o que el que se case sea Ibía, pues el hijo "no iba a casar a su padre anciano", según el mismo argumento. Por fin, no hay ninguna evidencia de que Echave Orio haya sido el único Echave que pasó a la Nueva España, pues como señaló el mismo Toussaint, citando al conde de Urquijo, un hermano de este artista hacia frecuentes viajes a estas tierras.

De la argumentación de Toussaint sobre la fecha del matrimonio suige la afirmación de la existencia de tres artistas homónimos: Baltasar de Echave, Orio, lbia y Rioja, reclamando como antecedente la referencia - ya citada- de Sigüenza y Góngora en las Glorias de Querétaro, donde este autor se refiere a "tres artistas del mismo nombre".

Para complicar aún más el panorama, en una de las cláusulas del testamento otorgado por José Juárez el 22 de diciembre de 1661, este artista declaró que "Baltasar de Chávez, pintor, me es deudor de cuarenta y nueve pesos que le dí en reales..." 17 Este dato fue interpretado por quien publicó el documento: "este pintor no es otro que Baltasar de Echave Ibia", ${ }^{18}$ sin lugar a error, pues repite "debe haber ejercido [José Juárez] una importante influencia en el círculo de artistas que lo rodeó y formó parte de su taller entre los que encontramos a... Baltasar de Echave Ibía..." 19 Según Toussaint, Echave Ibía debió nacer alrededor de $1582-1583$ y por lo tanto, para 1661 tendría aproximadamente setenta y ocho años. ¿No es extraño que un artista como Echave Ibía, que se supone fue contemporáneo de Luis Juárez, forme parte y sea deudor del taller del hijo de este último?

y el Retrato de Dama de fecha muy cercana, todas obxas de la Pinacoteca Virreinal de San Diego.

16 Tal es el caso del pintor Diego de Borgraf, por citar sólo un ejemplo en el campo del arte.

17 Efraín Castro, "El testamento de José Juárez", en Boletin de Monumentos. Histónicos, México, INAH, 1981, núm. 5, p. 9.

18 Ibidem, p. 5 .

19 lbid., p. 7 . 
Por otra parte, la hipótesis de Toussaint ubica la muerte de Echave Ibia alrededor de 1650. ¿Por qué entonces Efraín Castro alude tan direc. tamente a Echave Ibía, cuando Diego Angulo, que también conoció el testamento de Juárez, interpreta el mismo dato como referencia a Echave Rioja? ${ }^{20}$ El conocimiento que Castro tiene de la documentación de la época colonial novohispana y que ha publicado sólo en mínima parte, alerta sobre la posibilidad de la existencia de un dato no conocido hasta el momento que obligaría a revisar rigurosamente las fechas para Echave Ibía, aunque no debe descartarse de manera definitiva la posibilidad de un error en la intexpretación del documento.

Estas son algunas de las interrogantes que no hacen más que justificar la necesidad de abarcar el estudio de los Echave en su totalidad; un proyecto ambicioso pero imprescindible, pues si bien los trabajos parciales que se han intentado sobre el tema, son valiosos esfuerzos de aproximación, es aún tal la confusión de personalidades, obras y atribucicnes que existe entre estos artistas, que es casi una obligación considerar el problema en su conjunto. ${ }^{21}$

Un claro ejemplo de la problemática planteada en el párrafo anterior, es la pintura que se presenta en este artículo, que abre nuevos aspectos en la consideración de la obra de estos artistas.

\section{¿Quién fue Manuel de Echave?}

Ya se mencionaron algunas citas, sobre el ínfimo conocimiento que se tuvo y se tiene sobre este pintor. En 1872 Couto dice conocer de él un cuadro "apaisado, con figuras del Niño, la Virgen y San José, de medio cuerpo". Es casi seguro que se refirió a La Sagrada Familia que figuró después en el catálogo de la colección Barrón, de los cuales, cuar dro y catálogo, sólo quedan referencias escritas. En la misma obra, Couto sentenció al pobre Manuel con esta frase: "si no hacía cosas mejores que ésa, no merecía que se le mencionara, a no ser por el apellido que.

20 Diego Angulo Iñiguez, Historia del Arte Hispanoamericano, Madrid, Salvat Editores, 1950 , vol II, p 399 .

21 Consideramos aquí el trabajo de Rogelio Ruiz Gomax, op. cit, Gibson Danes, "Baltasar de Echave Ibía. Some Crititcal Notes on the Stylistic Character of His Art", en Anales IIE, núm. 9, para Echave Ibía; así como el de José Guadalupe Victoria (en preparación para Echave Orio. La autora de este artículo está trabajando desde hace varios años, un estudio sobre este tema: Los Echave, una familia de artistas de la Nueva España. 
lleva y acaso atestigua su deuda de sangre con los dos de quienes he hablado [Orio y Rioja]". Y por si quedara alguna duda de la opinión que la obra de Manuel le merecía, concluyó: "de suerte entonces que pudiera aplicársele en el Nobiliario de las artes el dicho del poeta latino: ... Perit omnis in illo nobilitas, cuyus laus est in origine sola"..22

Con pocos años de diferencia y de criterio, Fernández Villa le dedicó unas líneas: "Manuel Echave, muy inferior a los dos anteriores [Orio y Rioja] aunque sus obras no pueden juzgarse despreciables", 23 Un poco menos exigente que Couto parece, además, que Fernández Villa vio más de una obra de Manuel. Diez Barroso lo calificó como un pintor "de insignificante mérito artístico" y dice que lo cita "sólo a manera de memoria". ${ }^{24}$

La suerte parecía estar echada para Manuel, pero, como en muchos otros casos, fue Toussaint quien al elaborar su hipótesis sobre los Echave y reconocer la personalidad artística de quien él mismo llamó Echave Ibía, el de los azules, dejó entrever la posibilidad de que fueran de Manuel, hermano de Baltasar, muchas de las obras atribuidas a este último

Abelardo Carrillo y Gariel tuvo la fortuna de identificar la primera obra de Manuel, una Imposición de la casulla a San Ildefonso. El cuadro había sido rescatado de las bodegas de la Academia de San Carlos por Jorge Enciso, cuando ejercía funciones de jefe del Departamento de Monumentos Coloniales. De allí la obra pasó al Museo de Churubusco, donde figuraba como pintura anónima ${ }^{25}$

Este óleo sobre lienzo de 215 por 167 centímetros, está firmado en lo que simula ser una tarjeta doblada en el centro de la parte inferior del cuadro: Manuel de Echave faciebat $A{ }^{\circ} 1628$. Para 1974 la firma habia desaparecido bajo sucesivos repintes pero en 1980 por obra de la restauración, reapareció claramente tal como la había descrito Carrillo y que quien escribe pudo ver. Pero, al organizar el Museo de las Intervenciones, algunas de las pinturas coloniales que pertenecían a Churubusco, fueron amontonadas en oscuros pasillos del viejo convento y las demás

22 J. B. Couto, op cit, p. 17

23 Fernández Villa, op. cit., p. 39-40.

24 Diez Barroso, op. citi, p. 278.

25 Éste autor se ocupó de la obxa en Técnicas de la pintura en Nueva España, México, UNAM-IIE, 1946; Autógrafos de pintores coloniales, México, UNAM-IIE, 1953 y en "Tres firmas desaparecidas" en Retablo Barroco a la memoria de Francisco de la Maza, México, UNAM-IIE, 1974 
no están en exhibición, entre las cuales se halla esta única pintura conocida de Manuel de Echave.

El cuadro que se da a conocer aquí, si bien aumenta el poco conocimiento que existe sobre la obra del artista, tiene además la importancia de ser una de las raras pinturas coloniales firmada por dos artistas. En efecto, esta Inmaculada Concepción, está firmada y fechada Manuel \& $B^{r}$ de Echave faciebant 1625. ${ }^{26}$ La comparación de ambas firmas arroja algunas similitudes importantes, especialmente en el nombre Manuel aunque la $\mathbf{E}$ de Echeve se asemeja más a la utilizada por Orio en algu. na de sus obras, como la Adoración de los Magos de la Pinacoteca Virreinal.

El hallazgo de esta Inmaculada fue producto de la casualidad: una pequeña fotografía de la firma tue publicada como ejemplo de un trabajo técnico de esta especialidad. En la foto, parecía leerse claramente Manuel... y al tener las fotografias de la obra, se completó la lectura de la firma tal como se indicó páriafos arriba. ${ }^{27}$ Se pensaba encontrar una obra de Manuel de Echave, pero al observar con mucho cuidado la firma, la certeza de que ésta es doble, fue total. Algunas de las consideraciones que pueden hacerse sobre este asunto son las siguientes:

1. Las familias de artistas no fueron un caso raro en la pintura colonial -los Echave o los Juárez son los ejemplos más famosos- pero aunque siempre se ha supuesto la formación y colaboración familiar, es posible que éste sea uno de los pocos casos que puedan ejemplificar esta actitud.

2. Podría también pensarse que, en algún momento de sus respectivas carreras, Manuel y Baltasar trabajaron juntos, aunque la Imposición del primero, de 1628 y el Bautismo de Cristo, del segundo, del mismo año, demuestran que ambos artistas trabajaban en forma independiente.

Todo lo que pueda decirse hasta el momento entra en el terreno de las hipótesis, por lo que sólo la imagen admite una lectura con menos posibilidades de error.

\section{La In maculada Concepción}

A pesar de ser una de las ideas más discutidas de la religión católica

26 Agradezco la amistosa colaboración de todos los que dedicaron su tiempo en la paciente observación de la firma y la techa.

27 La restauradora de la obra, señora Dolores Femández Ramírez, proporcionó las fotografías de esta pintura que pertenece a una colección particular de México. 
y de lo tardío de la declaración del dogma, el de la Inmaculada Concep. ción, fue uno de los temas favoritos de la pintura española así como de la novohispana.

En el claustro del Convento Franciscano de Huejotzingo, para considerar un ejemplo del siglo xvi, la Inmaculada aparece rodeada de los símbolos de la letanía, la filacteria con la inscripción Tota pulchra es amica mea et macula non est en te y culmina la composicion el Padre Eterno. La virgen aparece coronada con las doce estrellas; el sol detrás de la cabeza; las manos jun'tas a la altura del pecho y está parada sobre una media luna con las puntas hacia arriba. La mirada se dirige hacia abajo, indicando que la virgen desciende a la Tierra, pues fue elegida por Dios desde la eternidad, para cumplir con el plan de salvación de la humanidad. La imagen responde a la iconografía tradicional, sintesis del Antiguo y del Nuevo Testamento: la Sulamita del Cantar de los Cantares y la Mujer Apocalíptica de la que habla San Juan. 25

Las tablas anónimas del siglo xvi que se encuentran en el Museo Nacional del Virreinato, son magníficos ejemplos de este tipo iconogxáfico, aunque con ligeras variantes. En cambio, la Inmaculada Concep. ción de 1620, que, como ya se ha dicho, se considera obra de Baltasar de Echave Orio, presenta un importante cambio iconográfico. Es una sintesis entre la virgen que desciente, inmaculada, con los símbolos de la letanía y la Virgen Reina de los Cielos, coronada, que asciende a encontrarse con su hijo. La Inmaculada Concepción de 1622, tradicio. nalmente atribuida a Echave Ibía, repite con ligeras variantes -las manos separadas, una serpiente enroscada a la media luna- la anterior composición.

La Inmaculada objeto de este trabajo, de poca distancia temporal con las dos anteriores - 1625-, significa un profundo cambio iconográfico. En esta imagen que presenta a la virgen de medio cuerpo, han desaparecido los símbolos de la dignidad real y también los de la letanía Es una mujer joven, con la cabeza descubierta y el cabello ondeado que cae, suelto, cerrándose a la altura de la nuca y cubriendo los hombros. Por detrás, rayos de sol iluminan la cabeza, rodeada por trece estrellas, en vez de las doce que corresponden.

En el rostro resuenan los ecos sevillanos de aquellas vírgenes creadas

${ }^{23}$ Cfr. Louis Reau, Iconographie de l'art chretien, Paris, Presses Universitaires de France, 1950, vol. II, parte 2, Emile Male, El arte religioso del siglo XII al XVIII, 2a ed, México, F. C.E. 1966 y Manuel Trens, Maria Iconografia de la Virgen en el arte español, Madrid, Ed. Plus-Ultra, 1946. 
por Luis de Vargas a mediados del siglo xvr y que calaran tan hondo en la imaginería de aquellas tierras. La cara es ovalada; la frente amplia; las cejas levemente arquieadas; tanto los arcos superciliares como los párpados, ligeramente abultados y amplios; la nariz recta, construida con dibujo: y la boca pequeña, construida con color; la barbilla redondeada continúa en sombras ascendentes que completan el óvalo. Las manos se inclinan hacia el costado derecho, con placidez y remiten al espectador al universo echaviano. Aunque las manos de Orio tienen una mejor construcción, en éstas, ninguna vena o articulación interrumpe la superficie amplia y lisa del dorso, mientras que los dedos, largos -separado y quebrado el meñique-, terminan en uñas bien dibujadas, con el implante curvo bien limitado y las falanges que las albergas levemente inclinadas hacia anriba.

A juzgar por los valores, habría distintos blancos en el cuello y la manga de la túnica de la virgen, así como una capa oscura - cazul?sobre la espalda. Los llamativos y artificiales pliegues de la manga izquierda parecen moverse en múltiples ángulos redondeados pues es notorio que, en forma sistemática, se evitaron las angulosidades que rompieran con la suavidad formal que caracteriza la composición. Sensibilidad plástica diferente a la del contemporáneo Luis Juárez, con sus paños angulosos de luces zigzagueantes y sus vírgenes niñas. Pero diferente también del austero español Francisco Pacheco, cuyas inmaculadas de fechas muy cercanas a ésta, son de dibujo cerrado y duro, aunque bien bien podrían considerarse como modelos españoles que serían pasados por el tamiz de la estética novohispana.

Sería muy difícil concluir en algún juicio sobre la calidad plástica de Manuel de Echave, a partir de dos obras. La intención al presentar esta pintura fue, en primer término, darla a conocer por ser un casn interesante, según lo que se ha considerado. En segundo lugar, quizás con el tiempo y la observación, pudieran encontrarse semejanzas con algunas de las obras atribuidas a Echave Ibía, que haga más comprensible la obra de este artista.

La histoxia del arte, construida con rigor científico pero con la sensibilidad abierta a las nuevas posibilidades, debe aceptar a Manuel sin los prejuicios de su contexto familiar. Los pioneros de la historia del arte en México, abrieron - hace ya muchos años- un camino que hay que volver a recorrer y que es necesario ampliar y mejorar. No todo está dicho ni todo lo dicho es lo correcto. Manuel Toussaint sería, sin duda -si esto fuera posible- uno de los compañeros de ruta. 
DOI: http://dx.doi.org/10.22201/iie.18703062e.1986.55.1277 
DOI: http://dx.doi.org/10.22201/iie.18703062e.1986.55.1277

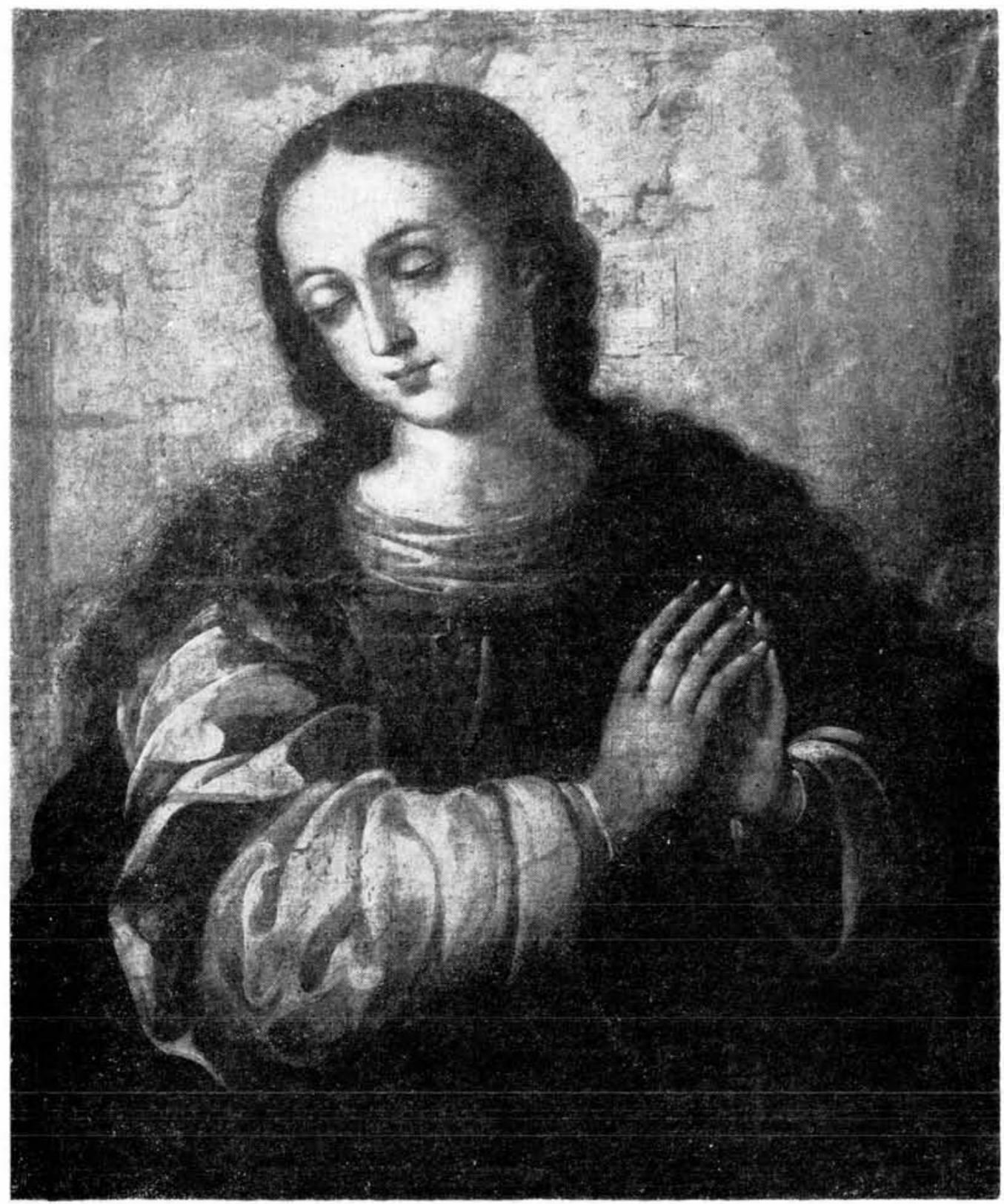

Figura 1. Manuel y Baltasar de Echave Ibia. La Inmaculada Concepción. 1625. La obra antes de la restauración. 


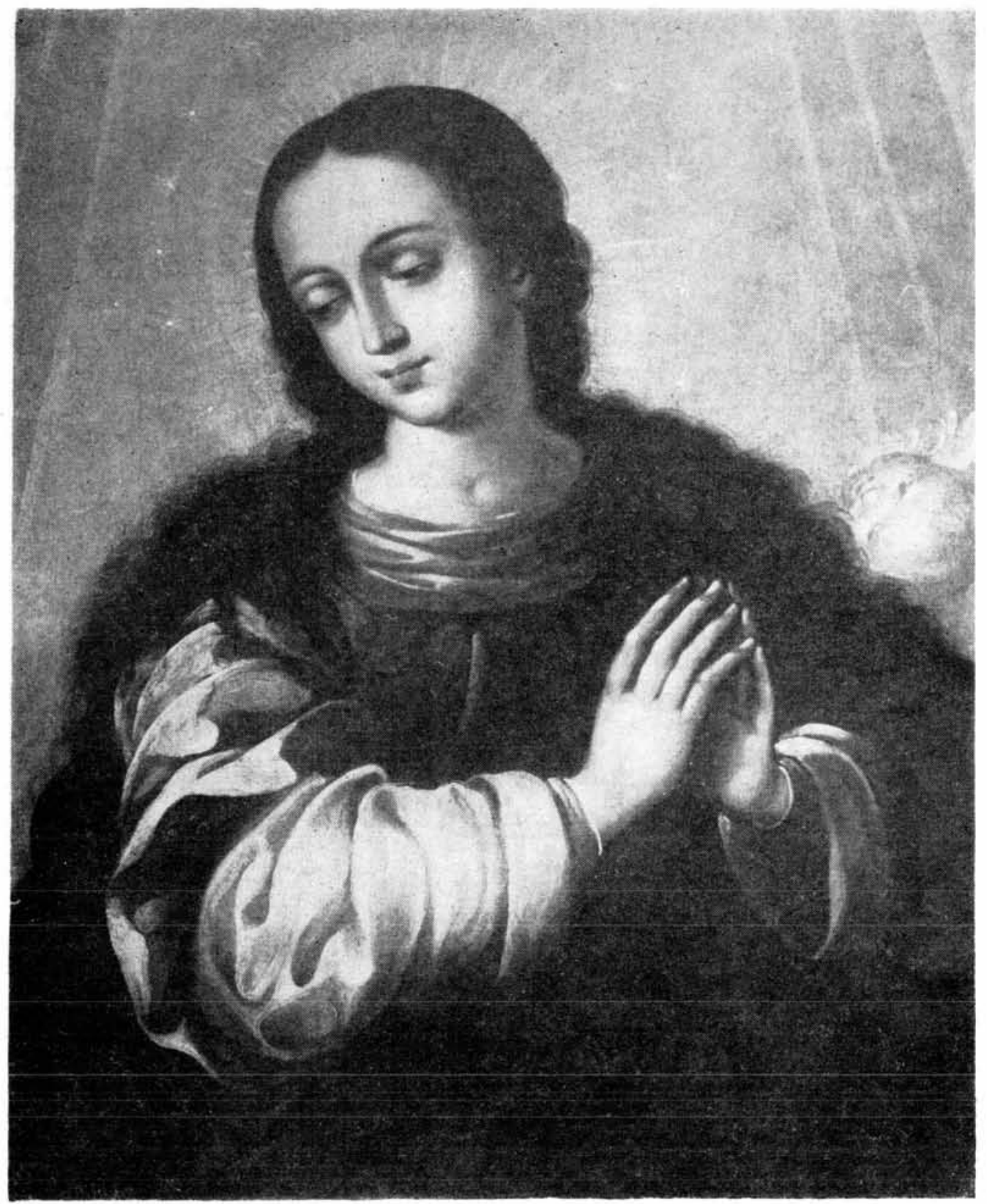

Figura 2. Manuel y Baltasar de Echave Ibía. La Inmaculada Concepción. 1625. La obra ya restaurada. Colección particular, México, D. F. 